\title{
CABS: A Conceptual Model For Context-Aware B2B Sales Applications
}

\section{Introduction}

In 2003, The Economist outlined a future in which sensor-enabled technologies would transform businesses as well as lives "The sentient office is coming", 2003). Given the ubiquity of smartphones, smartwatches and similar devices, this future has now arrived. Context-aware applications are now available that utilize the variety of sensors available on smartphones, wearable devices and other smart objects to detect the consumer's location, environment and behavior and deliver marketing content accordingly. The number and variety of these sensor-enabled networked devices is rapidly increasing, with analysts projecting growth in these devices to 26 billion by 2020 with an economic value-add of $\$ 1.9$ trillion (Jones, 2014; Prentice, 2014).

Unsurprisingly, the demand for context-aware digital marketing is growing rapidly as campaigns are proving to be effective and profitable for marketers and provide benefits for consumers (Brown and Harmon, 2014). In the retail environment, context-aware marketing has shown the potential to improve the shopping experience for the customer and the operational performance of the supplier (Chen et al., 2013; Ström et al., 2014). As mobile advertising is a fast growing channel, location and cross-device usage tracking is becoming a top priority for marketers, especially for retail outlets (McGuire, 2014). While many context-aware B2C applications are still new or in trial phase, they show promise in enhancing B2C sales and marketing activities. But the question arises, how can context-aware apps benefit B2B activities?

To date, innovations in Information Technology (IT) have had a considerable impact on the sales function in business-to-business sectors, bringing considerable benefits (Ahearne and Rapp, 2010; Ahearne et al., 2007; Boujena et al., 2009; Cardinali et al., 2014). Suppliers have gained from lowering the cost of sales by speeding up the sales cycle and/or reducing costs (Erffmeyer and Johnson, 2001) and increasing sales revenue by improving lead generation and enabling proactive selling (Ahearne et al., 2008; Rapp et al., 2008). New technology offers new opportunities for sales activities. Dow Corning are using combinations of electronic customer relationship management (e-CRM) and smartphone technologies to receive leads, monitor customer requirements and activity by location, and input orders in real-time (Grandhi and Chugh, 2012). The B2B sales community is increasingly using platforms such as LinkedIn for prospecting, customer follow-up and sales-related communications (Michaelidou et al., 2011; Moore et al., 2013). Advances in the quantity and quality of sensor technologies combined with the availability of customer insight data and ubiquitous networks, are enabling the rapid development of context-aware applications that can be deployed in sales and marketing activities (Columbus, 2012). One of the criteria for success will be the degree to which these new applications can provide customers with additional resource and value-creating potential (Saarijärvi et al., 2014).

In business-to-business relationships, a new world of networked devices is expected to create new opportunities for efficiency and value creation (Prentice, 2014). Business customers are showing a keen interest in mobile-enablement, 
expecting improved access to information to improve the value that can be achieved (Maoz and Desisto, 2014). For example, context-aware sensors are deployed to improve the efficiency of supply chains (Hwang et al., 2015). Purchasing decision-makers typically conduct technology-driven information searches before wishing to engage in conversations with suppliers (Holliman and Rowley, 2014). If data generated by context-aware technology can be integrated into business intelligence systems to improve the relevance and timeliness of information exchange, the more likely it would be that a problem could be solved and/or value might be exchanged. This would have value both for the customer's convenience and the supplier's sales performance.

This paper explores how context-aware technology can be deployed to collect and share information between buyers and sellers, thus enhancing the quality of the business relationship through alignment of customer need with supplier capabilities, i.e. supporting a co-creation of value. In particular, it addresses a number of research questions posed by Rodriguez et al (2014): how interactive technologies can improve buyer-seller relationships; how technologies and salespeople can work together to improve the process of co-creating value; and how information sharing enabled by new technologies may enhance customer relationships.

This article starts with a review of the literature discussing context-aware computing and its application in marketing, followed by consideration of the potential benefits of context-aware technology in B2B relationships, with a focus on supporting the co-creation of value between customer and supplier. A conceptual model for designing Context-Aware B2B Sales Applications (CABS) is proposed. This model could be used as a framework to develop ideas with both sales staff and customers about how contextual data can be used to accelerate the value creation process.

\section{Context-Aware Computing}

In IT, "context information" has been defined as "information that can be used to characterize the situation of "a...person, place or object that is considered relevant to the interaction between a user and an application" (Dey, 2001). Context-aware technology starts with tagging information from sensors, which will need to be combined with other data in order to be effectively used. It can be extended to present information or recommendations to a user, or it may even execute certain tasks, such as smart watering systems for gardens, machine-tomachine communication to switch on household appliance when the householder is on their way home (Perera et al., 2014). In an industrial scenario, a sensor in a machine could detect imminent failure and send a message to a 3D printer to create a replacement part (Prentice, 2014).

A context aware application uses the context of a person or object to deploy available resources to meet their needs. Contextual data should be analyzed within business intelligence systems to solve problems and manage services (Dai et al., 2014; Diallo et al., 2015; Perera et al., 2015). Context-aware systems "...acquire and reason about the context information and adapt the corresponding applications accordingly." (Makris et al., 2013, p. 362). Such applications typically require sensors to detect and collect contextual 
information, combined with appropriate hardware and software to store and process this information.

While context-aware applications and systems have existed since the early 1990s (Perera et al., 2014), advances in mobile technologies are leading to new opportunities in the development and use of these types of applications (Mehra, 2012). Smartphones may include sensors to detect such phenomena as location (GPS), physical and environmental information such as temperature, light, air pressure, movement (accelerometers), surroundings (in-built cameras) and identity (fingerprint scanners); some incorporate bio-sensors for health purposes (Perera et al., 2014). Smartphones also have the processing power to store and process this information, combine it with profile and usage information and interact with the user accordingly.

In consumer applications, mobile devices bring huge potential for context-aware personalization. For example data from sensors, social media and usage patterns from the mobile phone can be aggregated to produce applications that suggest products and services tailored to the individual consumer (Buhalis and Foerste, 2015). Such applications require sophisticated data mining and data modeling and can be particularly valuable in a service industry like tourism, where the quality of the customer experience is at high risk from environmental factors such as the weather (Buhalis and Foerste, 2015).

\section{Context -Aware Marketing}

Context-Aware Marketing (or Context Marketing) is defined as "marketing that is location-, time- and consumer profile specific" ("What is Context-Aware Marketing", n.d.). Others define it as "...combining insight about customers and prospects combined with personalization to deliver the right content to the right audience of users at the exactly the right time to satisfy the users' requirements..." (Swan, 2014). Scoble and Israel (2014) identify the five components of Context Marketing as

- Mobile Devices - originally laptops, but now primarily consists of smartphones, tablets and wearable technologies such as Google Glasses. Provides the platform for developing and promoting context-aware marketing.

- Social Media - facilitates not only communication but also personalization, providing information on consumer activities, plans and identity.

- Data - not only the data collected by context-aware applications, but also the plethora of data available on a consumer's individual and/or group behavior, preferences and attitudes. The goal in context-aware marketing is to combine all this data into customer insights to support forecasting and discover new opportunities.

- Sensors - includes not only the increasingly sophisticated sensors available on mobile devices, but also those now being built into static devices such as thermostats, appliances and industrial equipment.

- Location - the ability to identify the consumer's specific location, and thereby communicate marketing messages accordingly. 
The success of marketing is grounded in acquiring an ever deeper understanding of customer profiles, behavior and interaction preferences which enable the delivery of individualized offers (Stone and Woodcock, 2014). Indeed it is argued that consumers have reacted to the overload of choices available to them with demands for personalization (Buhalis and Foerste, 2015). Marketers therefore aspire to deliver "real-time, contextually-aware, personalized experiences" (Forrester Consulting, 2013, p. 2).

Combining basic geographic data with previous search or social media behavior has enabled delivery of marketing content that is not simply location relevant but also relevant to the user's interests or activities (Deighton and Kornfeld, 2009). However, the increased use of smartphones has expanded the potential for context marketing, given the ubiquity of these devices and the variety of context-detecting sensors available. For example, augmented reality ad-display (Blippar), travel apps, iBeacon positioning systems, Emu (monitors texts and makes suggestions /directions/reviews based on where you say you are going), Digital Assistants (Siri, Google Now), Payments (Apple Pay), A/R (Around Me, Augment, SnapShot Showroom), image recognition (CamFind), audio recognition (Shazam).

Context-aware applications are oriented to improving the consumer's experience and involvement in value (co-creation of value). For example, a typical application in tourism would be detecting a drop in temperature and increase in cloud cover, combining it with a user profile or usage patterns and recommending a visit to an art gallery rather than the beach, combined with a promotional voucher for the gallery (Buhalis and Foerste, 2015). Other examples include quicker access to stadium, merchandizing and catering for sports club members, performance data for skiers, self-service shopping and extra monitoring information in cars. RFID tags used in shops are not only used to make recommendations to consumers, but drive information up the supply chain to improve production and delivery efficiency (Hwang et al., 2015). Applications are becoming available that detect when participating consumers are in the vicinity of selected restaurants, and deliver menus and special offers to their mobile devices (Lunden, 2014).

\section{B2B selling and the creation of value}

In industrial settings and well as consumer scenarios, it is desirable for customers to be able to invoke services in response to dynamic identification of need (Dai et al., 2014). In B2B relationships, much emphasis has been put on developing the salesperson as an interpreter of customer need. "Value-based selling" (Terho et al., 2012; Töytäri et al., 2011) is selling behavior oriented to the potential for the supplier's competencies to create value for the customer. Terho et al.'s analysis of value-based selling identifies three core elements understanding the customer, developing the value proposition and communicating value in the customer's terms (Figure 1). The authors position their study in the customer-centric perspective of service-dominant logic (Vargo and Lusch, 2004), where service is a collaborative process in which a supplier applies competencies to deliver value-in-use to a customer. 


\begin{tabular}{|c|c|c|}
\hline $\begin{array}{l}\text { Understanding the } \\
\text { customer's business } \\
\text { model } \\
\text { Understanding the } \\
\text { customer's business logic } \\
\text { and goals to go beyond } \\
\text { customer expressed } \\
\text { needs in selling } \\
\text { Identifying substantial } \\
\text { drivers of value in the } \\
\text { customer's business, in } \\
\text { participation with the } \\
\text { customer }\end{array}$ & $\begin{array}{l}\text { Crafting the value } \\
\text { proposition } \\
\text { Active identification and } \\
\text { crafting of offerings that } \\
\text { have the potential to } \\
\text { impact the customer's } \\
\text { business profits based on } \\
\text { customer participation } \\
\text { and accumulated } \\
\text { knowledge } \\
\text { Quantifying the size of } \\
\text { the offering's value } \\
\text { opportunity to the } \\
\text { customer }\end{array}$ & $\begin{array}{l}\text { Communicating value } \\
\text { Credible demonstration } \\
\text { of how the offering can } \\
\text { contribute to the } \\
\text { customer's business and } \\
\text { business profits } \\
\text { Presentation of } \\
\text { quantified evidence, } \\
\text { openness and explicit } \\
\text { minimization of } \\
\text { customer risk, especially } \\
\text { through references and } \\
\text { guarantees. }\end{array}$ \\
\hline
\end{tabular}

Figure 1 (Terho et al., 2012)

Terho et al (2012) focus on the B2B salesperson as a facilitator of value creation with the customer, not just for the customer. To understand the customer requires knowledge of the customer's sector and markets, their own internal operations and their positioning with their own customers. The salesperson needs to understand the "social, spatial, temporal and physical contexts in which usage takes place" and how usage contexts change (Grönroos and Voima, 2013). This data can only be acquired with the co-operation of the customer, which will only be given where there are expectations that sharing information will ensure that the salesperson makes better proposals. Salespeople check their analysis through dialog with the customer before crafting and communicating offerings quantified to demonstrate their value generation potential. All stages of the process involve collaboration internally and externally via a variety of media.

The application of context-aware technology should be managed as a resourcebased service innovation and evaluated from the customer's perspective (Skålén et al., 2014). It is expected these technologies at least improve the quantity and quality of interactions between supplier and customer. Through interaction, suppliers can access the customer's value sphere to engage with how they create value for themselves and their customers (Grönroos and Voima, 2013). These interactions must lead to the enhancement of joint decision-making in order to realize service benefits for the customer (Wong et al., 2014). Wherever technology has been applied at the supplier-customer interface, mutual value must be planned and measured. For example, in the case of vendor-managed inventory where there are clear benefits to the supplier of having access to the customer's processes, the technology must also deliver measurable cost savings, cash flow improvements, reduced obsolescence and improved forecast accuracy to the customer (Zachariassen et al., 2014). 


\section{Context-aware B2B selling}

Context-aware B2B selling can be defined as the integration of information about the customer's situation with business intelligence to enable meaningful recommendations and communications throughout the sales process. It is expected that this application of technology can facilitate co-creation of value between buyer and seller by giving both access to timely and relevant information about operational needs. Supplier sales activity will be linked more closely to the customer buying cycle. The supplier and customer can also benefit from a reduction in the amount of salesperson time deployed in information gathering and analysis. The customer can also use the data generated, such as product performance, usage patterns, emissions monitoring and asset/stock movements to achieve process optimization (Saarijärvi et al., 2014; Skålén et al., 2014).

To date, scenarios of context-awareness applied to selling have focused on improving the productivity of the salesperson, such as mobile extensions of SFA (vom Brocke et al., 2014; Diallo et al., 2015). If salespeople are to be consultants to buying decision makers, context-aware technology should enable them to be even more responsive in providing value-adding information to customers, in particular where that information is location-dependent, requires personalization to a particular customer, and is time-critical. For instance, these technologies may enable the salesperson to adjust their travel plans in order to attend a local trade show, or track deliveries or service staff availability for customers (BenMoussa, 2005a). Information such as adjustments to a call plan to avoid a traffic problem, or address an incoming enquiry or cancelled order from a customer, or respond to information about competitor activity in an area, can be delivered in a timely and location-specific manner to the salesperson (BenMoussa, 2005a).

Context-aware applications encompass salesperson productivity, but have much more potential. Context-aware technology can go further than Electronic Data Interchange (EDI) in automating the integration of the supplier's sales process with the customer's buying process, because sensors in equipment can trigger orders for new materials or parts. This has value for the customer in reducing transaction costs. Suppliers offering such convenience are differentiating themselves by improving their "ease of doing business" (Stading and Altay, 2007). The more that context-aware technology can improve the relevance and timeliness of information exchange between suppliers and customers, the more likely it is that problems can be solved and value can be exchanged (Holliman and Rowley, 2014). Machine-to-machine interaction in production, delivery and service processes generates a data dialog that can improve the supplier's understanding of the customer leading to better proposals. As with B2C contextaware applications, the generation of data from sensors imbedded in customers' assets requires consent and co-ownership, enabling the customer to do their own information analysis (Saarijärvi et al., 2014).

Changing a sales model to one designed to maximize cost-effectiveness and convenience in the buying process can be successful. For example, buying enterprise application software has traditionally been a lengthy and costly 
process involving complex corporate buying centers, which can stifle innovation (Wenzel et al., 2012). The availability of software as a service from ICT suppliers (such as AppExchange from salesforce.com, Microsoft's Pinpoint and SAP's SAP Store) can enable customers in business sectors to purchase enterprise applications in an "app store way" (ibid). Reduction of complexity in the customer's buying situation, along with extensive use of technology to support consultative selling within an integrated multi-channel sales process, should provide benefits for supplier and customer (ibid).

This search for convenience equivalent to that in B2C context-aware applications appears to have been adopted to some degree in B2B, as companies enable allowable apps for employees involved in buying decisions (Beimborn and Palitza, 2013). BenMoussa's (2005b) identification of the importance of location, personalization and immediacy in interactions between suppliers and customers helps to identify where innovation can be successful. For example, a farmer in his/her fields could utilize a mobile app to analyze the state of the crop and what fertilizer might be needed. This could save valuable time in addressing a problem (Bunge, 2013). However, such examples are few and far between, suggesting more work needs to be done to identify and develop suitable context-aware applications for the B2B market. Technology tools, platforms and services are required to facilitate customer involvement in identification of new opportunities for value (Galvagno and Dalli, 2014).

Interaction that transcends beyond the selling-purchasing interface and enables the integration of operational plans would have even greater benefits for both supplier and customer (Plank and Hooker, 2014). Suppliers should facilitate customers' creation of their own value, and adapt to meet customers' needs (Grönroos and Voima, 2013). "Co-creation of value is the joint, collaborative, concurrent, peer-like process of producing new value, both materially and symbolically." (Galvagno and Dalli, 2014, p. 644). Development of context-aware applications implies that customer and supplier systems must be open to each other. Radio-frequency identity devices (RFID), sensors and actuators are becoming integral components of networks and data gathering to enable intelligent interactions (Maoz and Desisto, 2014; Perera et al., 2014). Systems that automate activity between buyer and seller have been critical in driving supply chain efficiencies (Plank and Hooker, 2014).

The value-creation process should be embedded within the customer's buying process (Dixon and Tanner, 2012), and the concept of embedding technology within the customer's operational contexts to trigger value-creating conversations is an application of that principle. Sales professionals do not start or control interaction, but diagnose opportunities for value and co-create the outcome with the customer.

For interactive technologies to improve buyer-seller relationships, the provision of relevant information in a timely manner is a critical starting point. Just as it is possible for context-aware marketing to make recommendations to a tourist on a rainy day, it is possible for context-aware technology to identify changes in how a customer's machine is being deployed, how stock is moving or how a service outlet is operating. It can trigger recommendations to both the customer and the 
supplier about productivity adjustments and order requirements. Real-time alerts can be combined with customer insight data to prompt salespeople to make pro-active proposals to customers. Both the salesperson and customerdecision maker can use the data for modeling new solutions. Each context-aware application can address a part of the selling/buying process or combine with others to produce more comprehensive solutions. Since the customer has to allow the capture of context-aware data, the convenience of the customer and the value of the application to them will be the driving force.

\section{Modeling the Context-Aware B2B Sales Cycle}

In order to develop applications suitable for any type of B2B activities, a structured approach is needed that facilitates the understanding and analysis of the organization's processes, and provides a suitable "roadmap" for integration of the applications (Bal, 2013). For context-aware B2B sales applications, this approach needs to integrate the process of context-aware application development with that of the B2B sales cycle, in order to produce a model that can guide sales academics and practitioners in identification and exploitation of context-aware technologies.

There are a number of models and taxonomies, developed specifically for technical audiences, which describe the stages in design and development of context-aware technologies across a variety of environments, including Enterprise Applications, General IT, The Internet of Things and Mobile Search Engines (Bal, 2013; Dey, 2001; Perera et al., 2014; Yndurain et al., 2012). To provide a simple model that addresses the general development of mobile context-aware applications, Makris et al. (2013) divide the common functionalities of Context Aware Mobile and Wireless Networking (CAMoWiN) applications into a Context Modeling Taxonomy (Figure 2):

\begin{tabular}{|c|c|}
\hline ring & $\begin{array}{l}\text { - Monitor, gather, evaluate and classify the raw data } \\
\text { gathered by sensors into contextual information. }\end{array}$ \\
\hline & $\begin{array}{l}\text { - Interpret, reason from, store/retrieve and predict/ } \\
\text { learn from the contextual information. }\end{array}$ \\
\hline $\begin{array}{l}\text { xchanging } \\
\text { he Context }\end{array}$ & $\begin{array}{l}\text { - Identify the entities that potentially interact with the } \\
\text { contextual information, personalise and disseminate } \\
\text { the contextual information accordingly. }\end{array}$ \\
\hline
\end{tabular}

Figure 2 - Context Modelling Taxonomy (Perera et al., 2014) 
For the B2B Sales Cycle, the Value-Based Selling Behavior model shown in Figure 1 (Terho et al., 2012) has been used. This widely cited recent article has been recognized as a contribution to the co-creation of value literature (Galvagno and Dalli, 2014). It offers three clear stages in B2B selling which align with the CAMoWIN model: understanding the customer's contexts; alignment with supplier capabilities to identify an offer; and communication of the offer. It therefore is a useful platform for exploring the application of context-aware technology to the B2B sales process.

The next step in modeling a Context-Aware B2B Sales Cycle is to examine how the Context Modeling Taxonomy shown in Figure 1 can be applied to each stage of Terho et al.'s Value-Based Selling model to identify potential context-aware applications that can contribute to particular aspects of the B2B sales cycle.

\section{Understanding the Customer's Business Model}

The first stage of the value-based selling model centers on first knowing what the customer needs, in participation with the customer. Achieving this knowledge involves not just comprehension of the customer's explicitly stated requirements, but also understanding their business model, unarticulated needs and future trends. Applying the Context Modeling Taxonomy to this stage identifies how contextual data can be gathered, processed and disseminated to support this understanding (Figure 3).

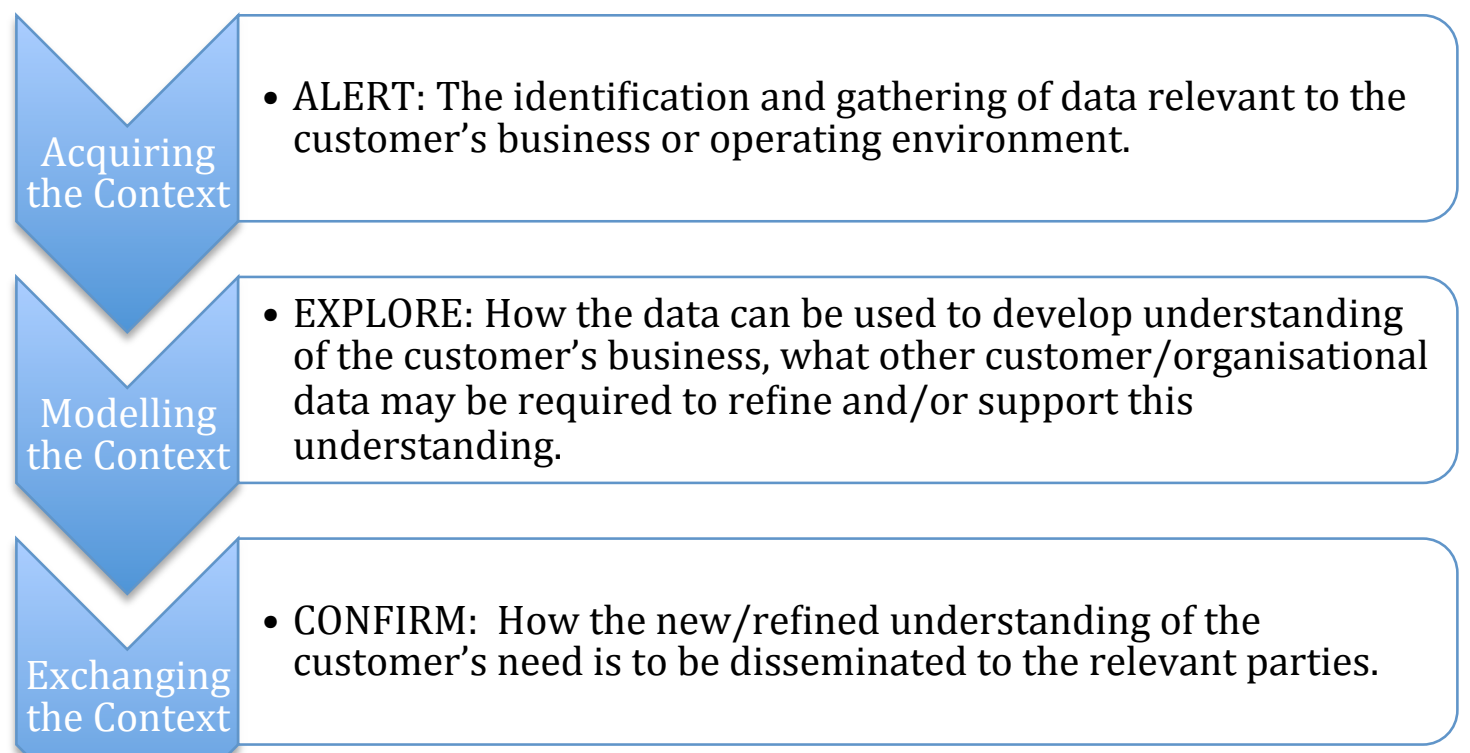

Figure 3: Context-Aware support in understanding the customer's business model 
To demonstrate how the above can be used to identify a suitable mobile contextaware application, take as an example that of the customer who is a large agribusiness. In this case, the needs of this business could be affected by changes in weather, particularly for microclimates, which could impact crop yields and market pricing. This suggests that new customer requirements for different types of fertilizer and/or pesticides may arise and need to be quickly identified and communicated to the supplier of these products. Mapping this example against the Context-aware model illustrates where and how context-aware data can support the understanding of the customer's business model, identifying a potential context-aware application to benefit both the agribusiness customer and the agrichemical salesperson (Figure 4).

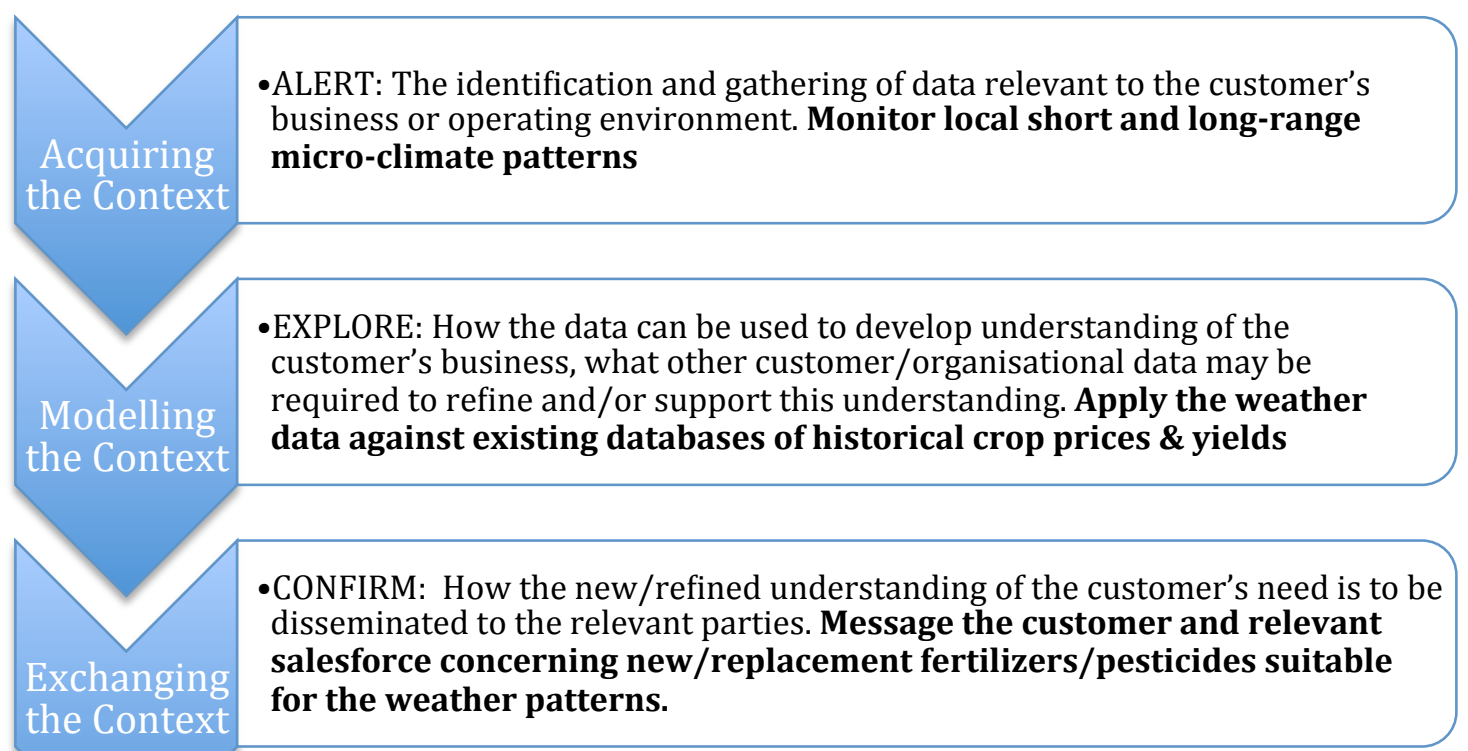

Figure 4: A proposed agribusiness context-aware application

\section{Crafting the value proposition}

The second dimension of the value-based selling model centers on the identification of specific problems and development of solutions that bring quantifiable benefits to the customer, in participation with the customer. Applying the Context Modeling Taxonomy to this stage identifies how contextual data can be gathered, processed and disseminated to support solution development and value quantification (Figure 5): 
- INTERROGATE: The identification and gathering of the data needed to craft the solution.

- ANALYSE: The modelling of the contextual data, along with other customer, seller and market data into a business solution.

Modelling

the Context

PROPOSE: The development of the business solution into a proposal.

Exchanging

the Context

Figure 5: Context-Aware support in crafting the value proposition

To demonstrate how the above can be used to identify a suitable mobile contextaware application, take as an example that of the customer who is a factory owner. In this case the customer may be in need of replacement parts for their assembly-line machinery. Normally the customer would contact the relevant supplier for a particular component, the supplier would in turn look at their inventory of parts and what had been supplied to the customer in the past and then identify the specific parts to supply the customer. Mapping this example against the Context-aware model illustrates where and how context-aware data can support crafting the value proposition, identifying a potential context-aware application that would benefit both the factory customer and the assembly-line equipment salesperson (Figure 6). 
-INTERROGATE: The identification and gathering of the data needed to craft the solution. Factory owner takes a photo of the required component, which is transmitted to the supplier.

-ANALYSE: The modelling of the contextual data, along with other customer, seller and market data into a business solution. The customer's photo is automatically compared against the supplier's database of assembly-line components and

Modelling customer's previous orders to identify the relevant part and possible add-on sales.

PROPOSE: The development of the business solution into a proposal. The customer is messaged to alert them of part availability and order process, while the salesperson is messaged to alert them of the customer's requirement and upselling opportunity.

Figure 6: A proposed context-aware application for assembly-line customers and suppliers

\section{Communicating value}

The third dimension of the value-based selling model centers on communication of the value proposition to the customer. The goal of this communication is to work with the customer in order to enable evaluation of the proposed solution, and therefore should include not just the quantifiable value to the customer's business, but also "soft" issues such as trust and risk avoidance. Applying the Context Modeling Taxonomy to this stage identifies how contextual data can be gathered, processed and disseminated to support this communication (Figure 7): 
-ASSESS: The identification and collection of hard and soft contextual data relevant to the solution.

-EVALUATE: The valuation of the solution, based on contextual hard/ soft cost data, market conditions and the customer's business environment.

-DEMONSTRATE: Communication of the solution's value, expressed in

Figure 7: Context-aware support in communicating value

To demonstrate how the above can be used to identify a suitable mobile contextaware application, take as an example that of a buyer of IT services for schools, who has recently received a proposal from their supplier to upgrade equipment. In this case the customer may be attending a trade show where a new tablet computer is being shown which is particularly suitable for educational purposes. However the risk-adverse customer is concerned as to the suitability of such cutting edge equipment for their environment, as well as how the pricing and availability will affect any proposed solution. Mapping this example against the Context-aware model illustrates where and how context-aware data can support communicating value, identifying a potential context-aware application that would benefit the customer as well as the IT salesperson (Figure 8). 
-ASSESS: The identification and collection of hard and soft contextual data relevant to the solution. Customer scans pictures, prices and technical information concerning the new tablet, as well as any additional questions, directly from the tradeshow.

-EVALUATE: The valuation of the solution, based on contextual hard/soft cost data, market conditions and the customer's business environment. The information from the tradeshow is processed by the IT solutions supplier, along with the customer's questions.

-DEMONSTRATE: Communication of the solution's value, expressed in the customer's terminology. The updated value proposition, along with answers to additional questions, is transmitted to the customer at the trade show, while the IT solutions supplier is sent recommendations for alleviating customer concerns and suggestions for price negotiation parameters with the tablet supplier.

Figure 8: Context-aware support in communicating value.

\section{The Context-Aware B2B Sales Model (CABS)}

As demonstrated above, the integration of an IT-focused context-aware development model with a B2B Sales-focused model produces a model that can assist the primary $\mathrm{B} 2 \mathrm{~B}$ stakeholders in identifying suitable context-aware mobile applications. This integrated model, CABS, is shown in Figure 9.


Figure 9 Context-Aware B2B Sales Model (CABS) 


\section{Managerial Implications}

Marketing departments and sales managers in B2B, in conjunction with their customers, should be working with their colleagues in IT to identify where context-aware technologies can be embedded in products and services to provide useful data, and how it can be combined with customer insight data and participation to prompt value-creating exchanges. The CABS model provided in this article is designed to be a framework for facilitating those conversations.

Consideration should be given to the degree to which context-aware applications could de-personalize value creation in B2B relationships. A large amount of buying in B2B is already automated, and portals and e-marketplaces are widely used. It could be accepted that there are some product repair or enhancement scenarios where the involvement of the salesperson is minimized by contextaware solutions. However, sales managers should bear in mind that the predictions of the 1990s that the sales profession could be replaced by electronic commerce have not been fulfilled; e-commerce and strategic selling are complementary. The skills profile of selling roles has changed in the past twenty years, with a focus on the salesperson providing strategic advice for innovative solutions to complex needs. Context-aware applications are most likely to provide key prompts and analysis to the salesperson to enhance and accelerate the process of value selling. The salesperson's creativity is unlikely to be programmable, even with the most sophisticated of sensors and analytic engines.

Meanwhile, as with all technology at the supplier/customer interface, care must be taken to design benefits for customers into the applications. Customer

consent for data gathering, and customer engagement in analysis will be essential to successful implementation.

\section{Future Research}

Having proposed the CABS model, the next step will be to gain feedback from relevant stakeholders concerning the suitability and comprehensiveness of the model. Initially, in-depth interviews with decision-makers exploring the potential of context-aware technology in their industry sectors would enable initial verification of the concepts, and identify scenarios in which case-based testing could be undertaken. Once the appropriate scenarios have been identified, testing of the CABS model could be done via Joint Application Design (JAD) activities, in which stakeholders work together to specify application requirements and design (Valacich et al., 2012). For the first CABS test, a prototype context-aware application will be designed for a specific organization via a JAD process that will include customers as well as sales, systems analysts and application developers. The JAD team will then be interviewed to assess the contribution of the CABS model in design of the prototype, along with suggestions for enhancements to the model for future use.

\section{Conclusion}

Rodriguez et al. (2014) call for the development of conceptual models that can drive research into the role of mobile marketing in professional selling. To meet this demand, the literature on IT adoption in B2B sales to support value selling 
has been combined with literature on context-aware marketing to produce a nine-step model, CABS, for integrating contextual data into the B2B sales process. While this paper specifically focuses on the sales process, the potential benefits of this model include the development of applications that provide more convenience and value creation for both supplier and customer across a range of activities, including operations and support. It is anticipated that qualitative research would be necessary to explore the attitudes of all stakeholders, and the potential application of this model.

\section{References}

Ahearne, M., Hughes, D.E. and Schillewaert, N. (2007), "Why sales reps should welcome information technology: Measuring the impact of CRM-based IT on sales effectiveness", International Journal of Research in Marketing, Vol. 24, pp. 336-349.

Ahearne, M., Jones, E., Rapp, A. and Mathieu, J. (2008), "High Touch Through High Tech: The Impact of Salesperson Technology Usage on Sales Performance via Mediating Mechanisms", Management Science, Vol. 54 No. 4, pp. 671685.

Ahearne, M. and Rapp, A. (2010), "The Role of Technology at the Interface Between Salespeople and Consumers", Journal of Personal Selling and Sales Management, Vol. 30 No. 2, pp. 111-120.

Bal, S.N. (2013), "Mobile Web - Enterprise Application Advantages”, International Journal of Computer Science and Mobile Computing, Vol. 2 No. 2, pp. 36-40.

Beimborn, D. and Palitza, M. (2013), “Enterprise App Stores for Mobile Applications - Development of a Benefits Framework", Proceedings of the 19 th Americas Conference on Information Systems (AMCIS), Chicago.

BenMoussa, C. (2005a), “Supporting salespersons' CRM efforts through locationbased mobile support systems", Journal of Systems Science and Systems Engineering, Vol. 14 No. 1, pp. 97-114.

BenMoussa, C. (2005b), "A Task-Based Framework for Mobile Applications to Enhance Salespersons' Performance”, Mobile Information Systems, Vol. 158, pp. 51-63.

Boujena, O., Johnston, W.J. and Merunka, D.R. (2009), “The Benefits of Sales Force Automation: A Customer's Perspective", Journal of Personal Selling and Sales Management, Vol. 29 No. 2, pp. 137-150.

Vom Brocke, J., Debortoli, S., Müller, O. and Reuter, N. (2014), "How in-memory technology can create business value: Insights from the hilti case", Communications of the Association for Information Systems, Vol. 34 No. 1, pp. 151-168. 
Brown, R.L. and Harmon, R.R. (2014), "Viral Geofencing : An Exploration of Emerging Big-Data Driven Direct Digital Marketing Services", Management of Engineering \& Technology (PICMET), 2014 Portland International Conference on, Portland, pp. 3300-3308.

Buhalis, D. and Foerste, M. (2015), "SoCoMo marketing for travel and tourism: Empowering co-creation of value", Journal of Destination Marketing \& Management, Elsevier, pp. 1-11.

Bunge, J. (2013), "Dow Chemical Wants its Software to Work in the Field, Literally", The Wall Street Journal, available at: http://blogs.wsj.com/corporate-intelligence/2013/12/17/dow-chemicalwants-software-to-work-in-the-field-literally/ (accessed 2 March 2015).

Cardinali, S., Gregori, G.L. and Palanga, P. (2014), "SFA Adoption : Empirical Evidences from A Case Study 1", International Journal of Business and Social Research, Vol. 4 No. 6, pp. 123-136.

Chen, C.C., Huang, T.C., Park, J.J. and Yen, N.Y. (2013), “Real-time smartphone sensing and recommendations towards context-awareness shopping", Multimedia Systems, Vol. 21 No. 1, pp. 61-72.

Columbus, L. (2012), "How Cloud Computing Is Accelerating Context-Aware Coupons, Offers and Promotions", Forbes, available at: http://www.forbes.com/sites/louiscolumbus/2012/12/27/how-cloudcomputing-is-accelerating-context-aware-coupons-offers-and-promotions/.

Dai, W., Liu, J.J. and Korthaus, A. (2014), "Dynamic on-demand solution delivery based on a context-aware services management framework", Ijguc, Vol. 5 No. 1, pp. 33-49.

Deighton, J. and Kornfeld, L. (2009), “Interactivity's Unanticipated Consequences for Marketers and Marketing", Journal of Interactive Marketing, Direct Marketing Educational Foundation, Inc., Vol. 23 No. 1, pp. 4-10.

Dey, A. (2001), “Understanding and using context”, Personal and ubiquitous computing, Vol. 5 No. 1, pp. 4-7.

Diallo, A.B.A., Badard, T., Hubert, F. and Daniel, S. (2015), “An OWL-Based Mobile GeoBI Context Ontology Enabling Location-Based and Context-Based Reasoning and Supporting Contextual Business Analysis", International Journal of Geosciences, Vol. 6 No. 1, pp. 88-108.

Dixon, A.L. and Tanner, J.F. (2012), "Transforming Selling: Why it is Time to Think Differently about Sales Research", Journal of Personal Selling and Sales Management, Vol. 32 No. 1, pp. 9-14. 
Erffmeyer, R.C. and Johnson, D. a. (2001), "An Exploratory Study of Sales Force Automation Practices : Expectations and Realities", Journal of Personal Selling and Sales Management, Vol. 21 No. 2, pp. 167-175.

Forrester Consulting. (2013), Delivering New Levels Of Personalization In Consumer Engagement.

Galvagno, M. and Dalli, D. (2014), "Theory of value co-creation: a systematic literature review", Managing Service Quality: An International Journal, Vol. 24 No. 6, pp. 643-683.

Grandhi, S. and Chugh, R. (2012), "Strategic Value of Mobile CRM Applications : A Review of Mobile CRM at Dow Corning and DirecTV", 2012 International Conference on Innovation and Information Management (ICIIM 2012), Vol. 36, pp. 388-394.

Grönroos, C. and Voima, P. (2013), "Critical service logic: Making sense of value creation and co-creation", Journal of the Academy of Marketing Science, Vol. 41 No. 2, pp. 133-150.

Holliman, G. and Rowley, J. (2014), "Business to business content marketing: marketers' perceptions of best practice", Journal of Research in Interactive Marketing, Vol. 8 No. 4, pp. 269-293.

Hwang, Y.-M., Kim, M.G. and Rho, J.-J. (2015), “Understanding Internet of Things (IoT) diffusion: Focusing on value configuration of RFID and sensors in business cases (2008-2012)", Information Development, pp. 1-17.

Jones, N. (Gartner). (2014), “Top 10 Mobile Technologies and Capabilities for 2015 and 2016", available at: https://www.gartner.com/doc/2665315/top-mobile-technologies-capabilities?docdisp=share\&srcId=1-4398736771 (accessed 11 June 2015).

Lunden, I. (2014), “Bookatable Tests Foodies' Appetite For iBeacons In UK, Shopkick Passes 7,500 Beacons", Techcrunch, available at: http://techcrunch.com/2014/10/15/bookatable-tests-restaurantsappetite-for-ibeacons-in-europe-while-shopkick-racks-up-7500-retailbeacons/ (accessed 28 November 2014).

Makris, P., Skoutas, D. and Skianis, C. (2013), "A Survey on Context-Aware Mobile and Wireless Networking: On Networking and Computing Environments' Integration", IEEE Communications Surveys and Tutorials, Vol. 15 No. 1, pp. 362-386.

Maoz, Mi. (Gartner) and Desisto, R.P. (Gartner). (2014), "The Future of Enterprise Applications Is Mobility", available at: https://www.gartner.com/doc/2793917/future-enterprise-applicationsmobility?docdisp=share\&srcId=1-4398736771. 
McGuire, M. (Gartner). (2014), “Gartner Mobile Marketing Scenario, 2015”, available at: https://www.gartner.com/doc/2945820/gartner-mobilemarketing-scenario-?docdisp=share\&srcId=1-4398736771 (accessed 11 June 2015).

Mehra, P. (2012), “Context-aware Computing”, IEEE Internet Computing, Vol. 16 No. 2, pp. 12-16.

Michaelidou, N., Siamagka, N.T. and Christodoulides, G. (2011), "Usage, barriers and measurement of social media marketing: An exploratory investigation of small and medium B2B brands", Industrial Marketing Management, Elsevier Inc., Vol. 40 No. 7, pp. 1153-1159.

Moore, J.N., Hopkins, C.D. and Raymond, M.A. (2013), "Utilization of RelationshipOriented Social Media in the Selling Process: A Comparison of Consumer (B2C) and Industrial (B2B) Salespeople", Journal of Internet Commerce, Vol. 12 No. 1 , pp. 48-75.

Perera, C., Member, C.H.L., Jayawardena, S. and Chen, M. (2015), “Context-aware Computing in the Internet of Things: A Survey on Internet of Things From Industrial Market Perspective", arXiv preprint arXiv:1502.00164, doi:10.1109/ACCESS.2015.2389854.

Perera, C., Zaslavsky, A., Christen, P. and Georgakopoulos, D. (2014), “Context Aware Computing for The Internet of Things: A Survey", IEEE Communications Surveys and Tutorials, Software Engineering; HumanComputer Interaction, , Vol. 16 No. 1, pp. 414-454.

Plank, R.E. and Hooker, R. (2014), "Sales and operations planning: Using the internet and internet-based tools to further supply chain integration", Journal of Research in Interactive Marketing, Vol. 8 No. 1, pp. 18-36.

Prentice, S. (Gartner). (2014), "The Five SMART Technologies to Watch", available at: https://www.gartner.com/doc/2669320/smart-technologieswatch?docdisp=share\&srcId=1-4398736771 (accessed 11 June 2015).

Rapp, A., Agnihotri, R. and Forbes, L.P. (2008), "The Sales Force TechnologyPerformance Chain: The Role of Adaptive Selling and Effort", Journal of Personal Selling and Sales Management, Vol. 28 No. 4, pp. 335-350.

Rodriguez, M., Dixon, A. and Peltier, J. (2014), "A review of the interactive marketing literature in the context of personal selling and sales management: a research agenda":, Journal of Research in Interactive Marketing, Vol. 8 No. 4, pp. 294-308.

Saarijärvi, H., Grönroos, C. and Kuusela, H. (2014), "Reverse use of customer data: implications for service-based business models", Journal of Services Marketing, Vol. 28 No. 7, pp. 529-537. 
Scoble, R. and Israel, S. (2014), Age of Context: Mobile, Sensors, Data and the Future of Privacy, Patrick Brewster Press, US, 1sted.

Skålén, P., Gummerus, J., von Koskull, C. and Magnusson, P.R. (2014), “Exploring value propositions and service innovation: a service-dominant logic study", Journal of the Academy of Marketing Science, pp. 1-22.

Stading, G. and Altay, N. (2007), "Delineating the 'ease of doing business'construct within the supplier-customer interface", Journal of Supply Chain Management, Vol. 43 No. 2, pp. 29-38.

Stone, M.D. and Woodcock, N.D. (2014), "Interactive, direct and digital marketing - a future that depends on better use of business intelligence", Journal of Research in Interactive Marketing, Vol. 8 No. 1, p. 12.

Ström, R., Vendel, M. and Bredican, J. (2014), "Mobile marketing: A literature review on its value for consumers and retailers", Journal of Retailing and Consumer Services, Elsevier, Vol. 21 No. 6, pp. 1001-1012.

Swan, S. (2014), “The FIve Forces of Context Marketing”, Smart Insights, available at: http://www.smartinsights.com/ecommerce/webpersonalisation/simon-swan-five-forces-context-marketing/.

Terho, H., Haas, A., Eggert, A. and Ulaga, W. (2012), "'It's almost like taking the sales out of selling'-Towards a conceptualization of value-based selling in business markets", Industrial Marketing Management, Elsevier Inc., Vol. 41 No. 1, pp. 174-185.

"The sentient office is coming." (2003), The Economist, available at: http://www.economist.com/node/1841108.

Töytäri, P., Alejandro, T.B., Parvinen, P., Ollila, I. and Rosendahl, N. (2011), "Bridging the theory to application gap in value-based selling", Journal of Business \& Industrial Marketing, Vol. 26 No. 7, pp. 493-502.

Valacich, J.S., George, J.F. and Hoffer, J.A. (2012), Essentials of Systems Analysis \& Design, Pearson Education, Upper Saddle River, 5thed.

Vargo, S.L. and Lusch, R. (2004), "Evolving to a New Dominant Logic for Marketing”, Journal of Marketing, Vol. 68 No. January, pp. 1-17.

Wenzel, S., Dirk, H., Mattfeld, C., Robra-bissantz, S., Institut, B., Faisst, W. and Burkard, C. (2012), "New sales and buying models in the internet: app store model for enterprise application software", Multikonferenz Wirtschaftsinformatik.

"What is Context-Aware Marketing." (n.d.). IGI Global, available at: http://www.igi-global.com/dictionary/context-aware-marketing/5638. 
Wong, C.W.Y., Lai, K.H., Cheng, T.C.E. and Lun, Y.H.V. (2014), “The role of ITenabled collaborative decision making in inter-organizational information integration to improve customer service performance", International Journal of Production Economics, Elsevier, Vol. 159, pp. 56-65.

Yndurain, E., Bernhardt, D. and Campo, C. (2012), “Augmenting Mobile Search Engines to Leverage Context Awareness", IEEE Internet Computing, Vol. 16 No. 2, pp. 17-25.

Zachariassen, F., Haas, H. De and Bürkland, S. (2014), "Vendor Managed Inventory: Why you need to talk to your supplier", Journal of Industrial Engineering, Vol. 7 No. 4, pp. 831-856. 